Supplement of Clim. Past, 16, 611-626, 2020

https://doi.org/10.5194/cp-16-611-2020-supplement

(C) Author(s) 2020. This work is distributed under

the Creative Commons Attribution 4.0 License.

(c) (1)

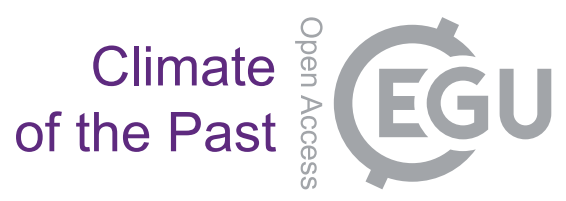

Supplement of

\title{
Extratropical cyclones over the North Atlantic and western Europe during the Last Glacial Maximum and implications for proxy interpretation
}

Joaquim G. Pinto and Patrick Ludwig

Correspondence to: Joaquim G. Pinto (joaquim.pinto@ kit.edu)

The copyright of individual parts of the supplement might differ from the CC BY 4.0 License. 

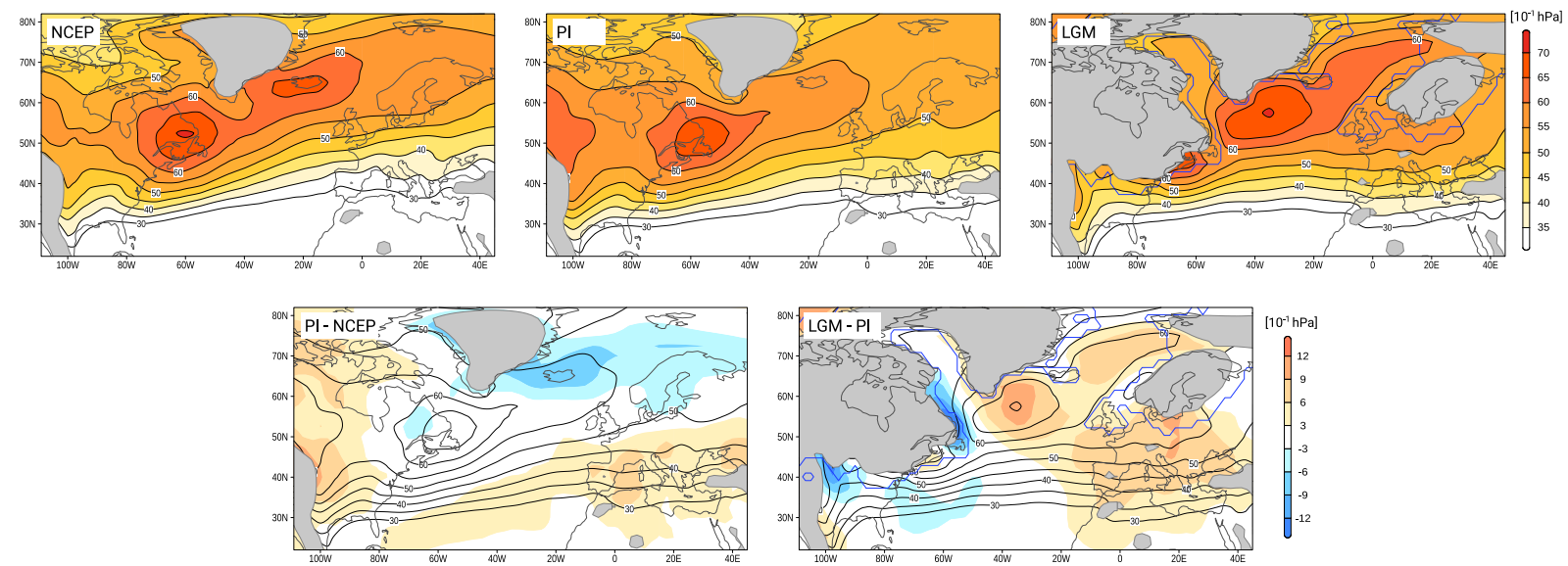

Fig. S1: Top: storm tracks (2-6 days band passed filter of daily MSLP data [1/10 hPa]) for the NCEP Reanalysis data and the MPI-ESM-P simulations for PI and LGM. Bottom: differences (shaded) between PI (lines) and NCEP and between LGM (lines) and PI. Areas with topography higher $1000 \mathrm{~m}$ shaded grey, LGM ice sheet extent marked by the blue line.
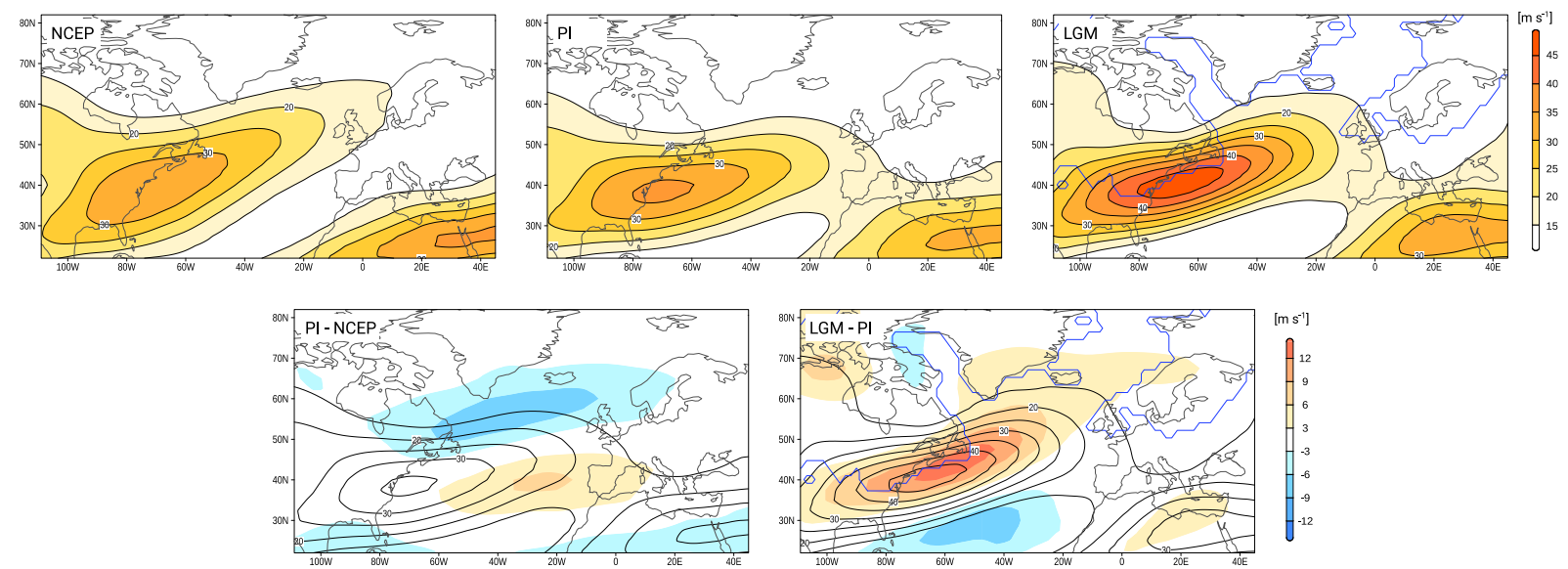

Fig. S2: Top: Upper level jet stream (wind speed at $300 \mathrm{hPa}[\mathrm{m} / \mathrm{s}]$ ) for the NCEP Reanalysis data and the MPIESM-P simulations for PI and LGM. Bottom: differences (shaded) between PI (lines) and NCEP and between LGM (lines) and PI. LGM ice sheet extent marked by the blue line. 

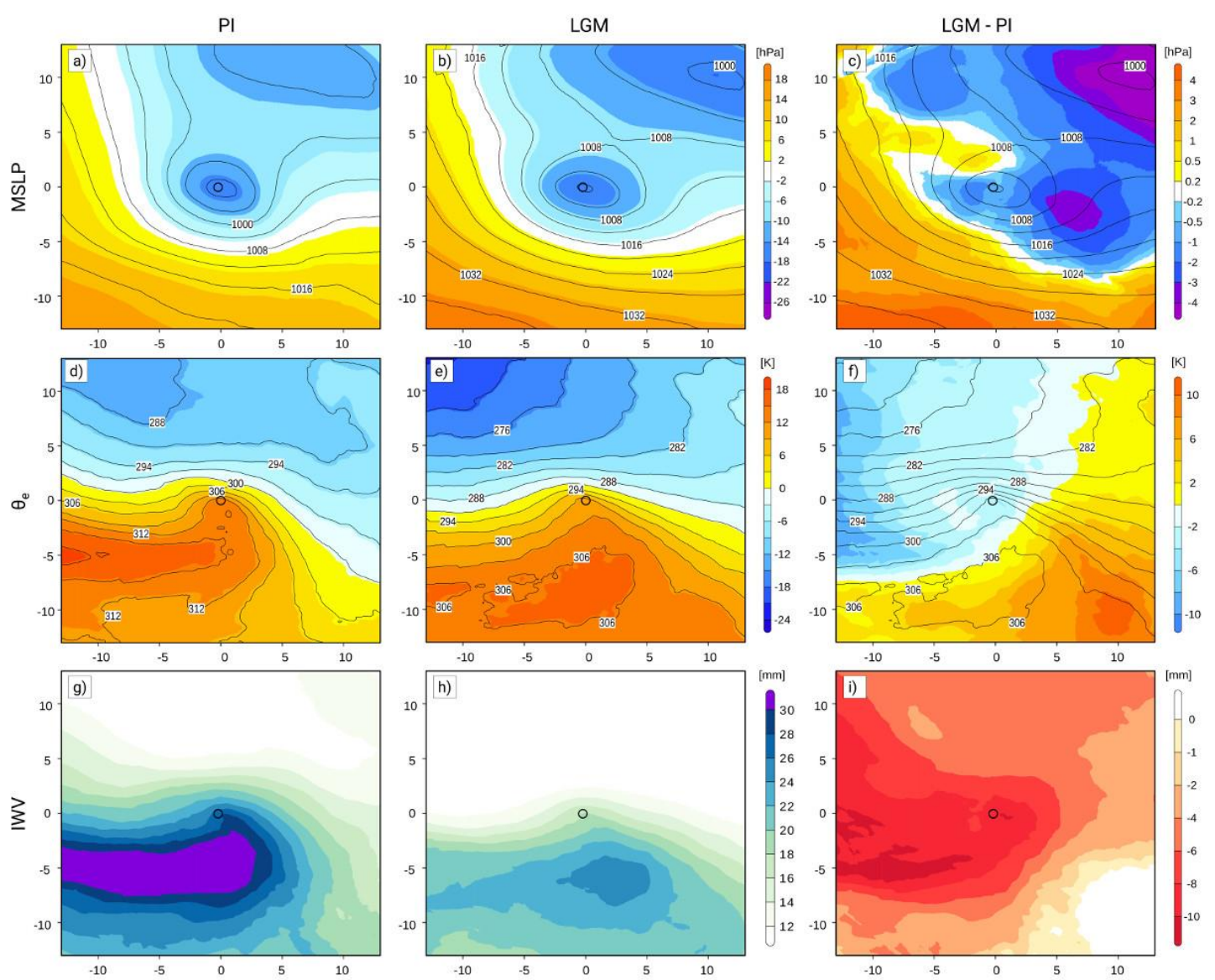

Figure S3. Composites of (a - c) mean sea level pressure, (d - f) ThetaE, and ( $\mathrm{g}-\mathrm{i}$ ) vertical integrated water vapour (IWV) for PI, LGM and difference LGM - PI 12 hours before peak intensity as defined by the maximum of the Laplacian of MSLP. (a, b) absolute MSLP values (lines, [hPa]), anomalies [hPa] from mean over displayed area (coloured); (c) absolute MSLP values (lines, [hPa]) from LGM, differences of the anomalies between LGM - PI in colours; (d, e) absolute ThetaE values (lines, [K]) and anomalies [K] from mean over displayed area (coloured); (f) absolute ThetaE values (lines, [K]) from LGM, differences of the anomalies between LGM - PI in colours; (g, h) absolute IWV values [mm], (i) difference [mm] LGM - PI. 

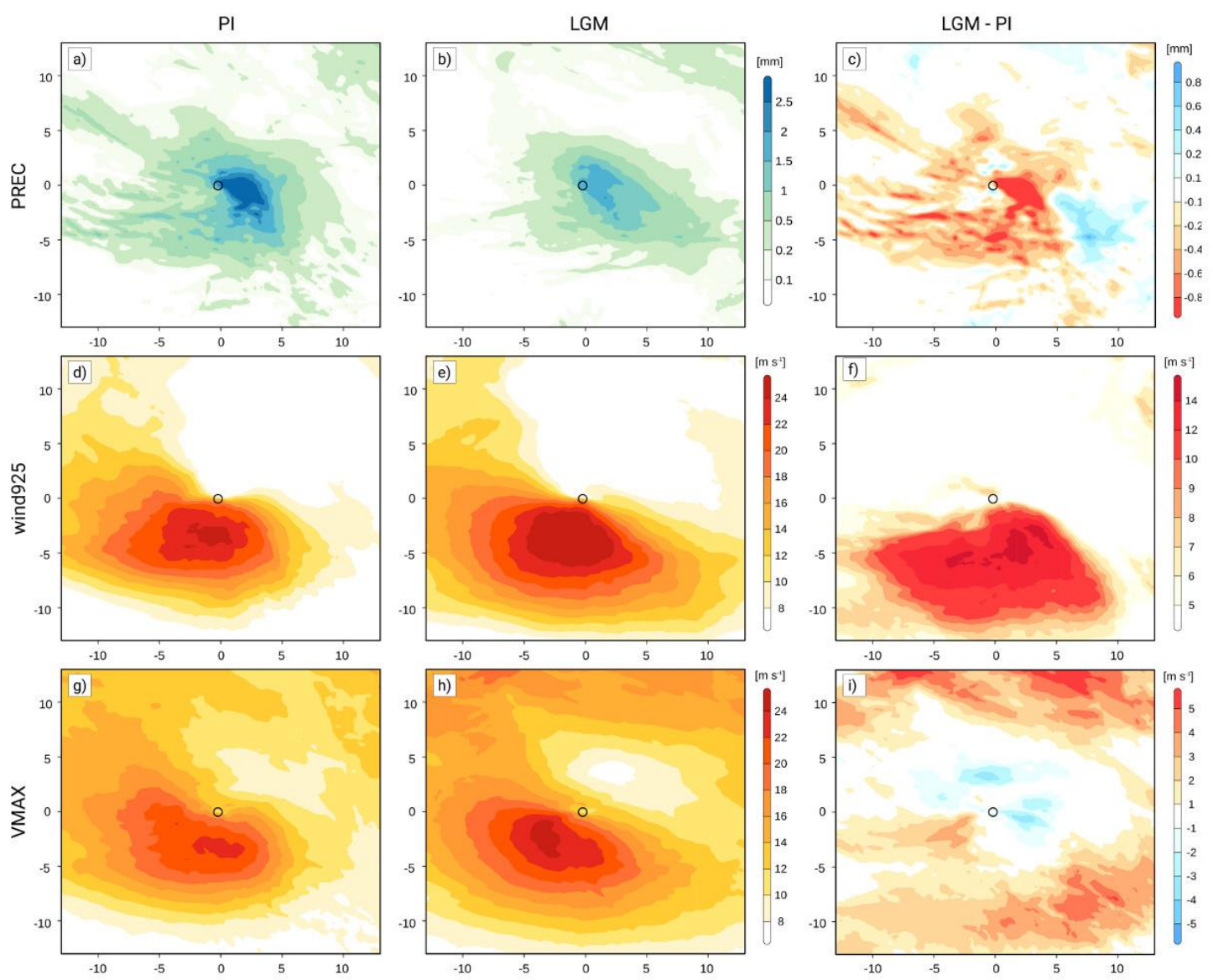

Figure S4. As Figure S3 but for hourly precipitation [mm] (a) PI, (b) LGM, (c) LGM - PI, (d - f) wind speed in $925 \mathrm{hPa}\left[\mathrm{m} \mathrm{s}^{-1}\right]$ and $\left(\mathrm{g} \mathrm{-} \mathrm{i)} \mathrm{maximum} \mathrm{near} \mathrm{surface} \mathrm{wind} \mathrm{gust}\left[\mathrm{m} \mathrm{s}^{-1}\right] 12\right.$ hours before peak intensity. 

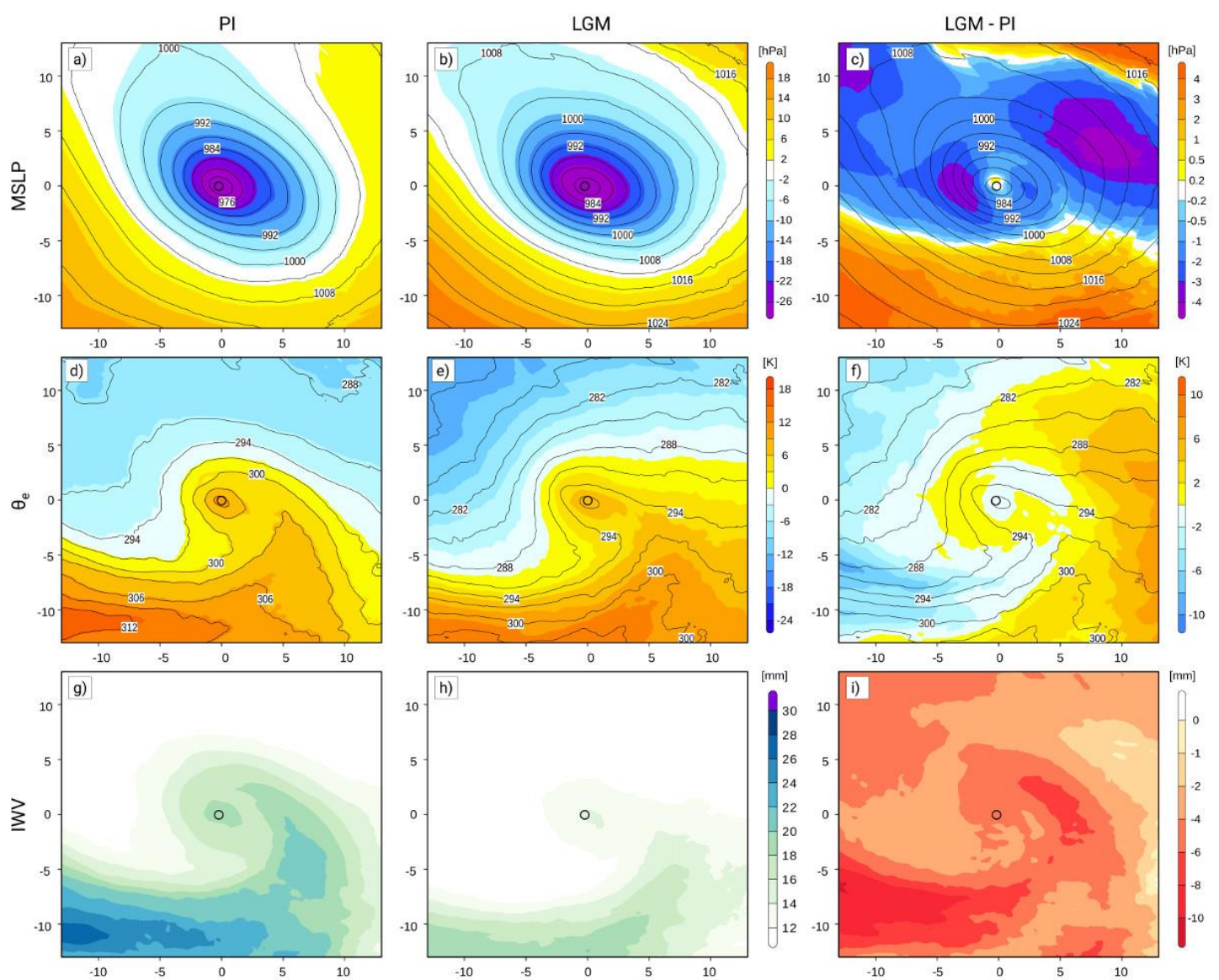

Figure S5. As Figure S3 but 12 hours after peak intensity. 

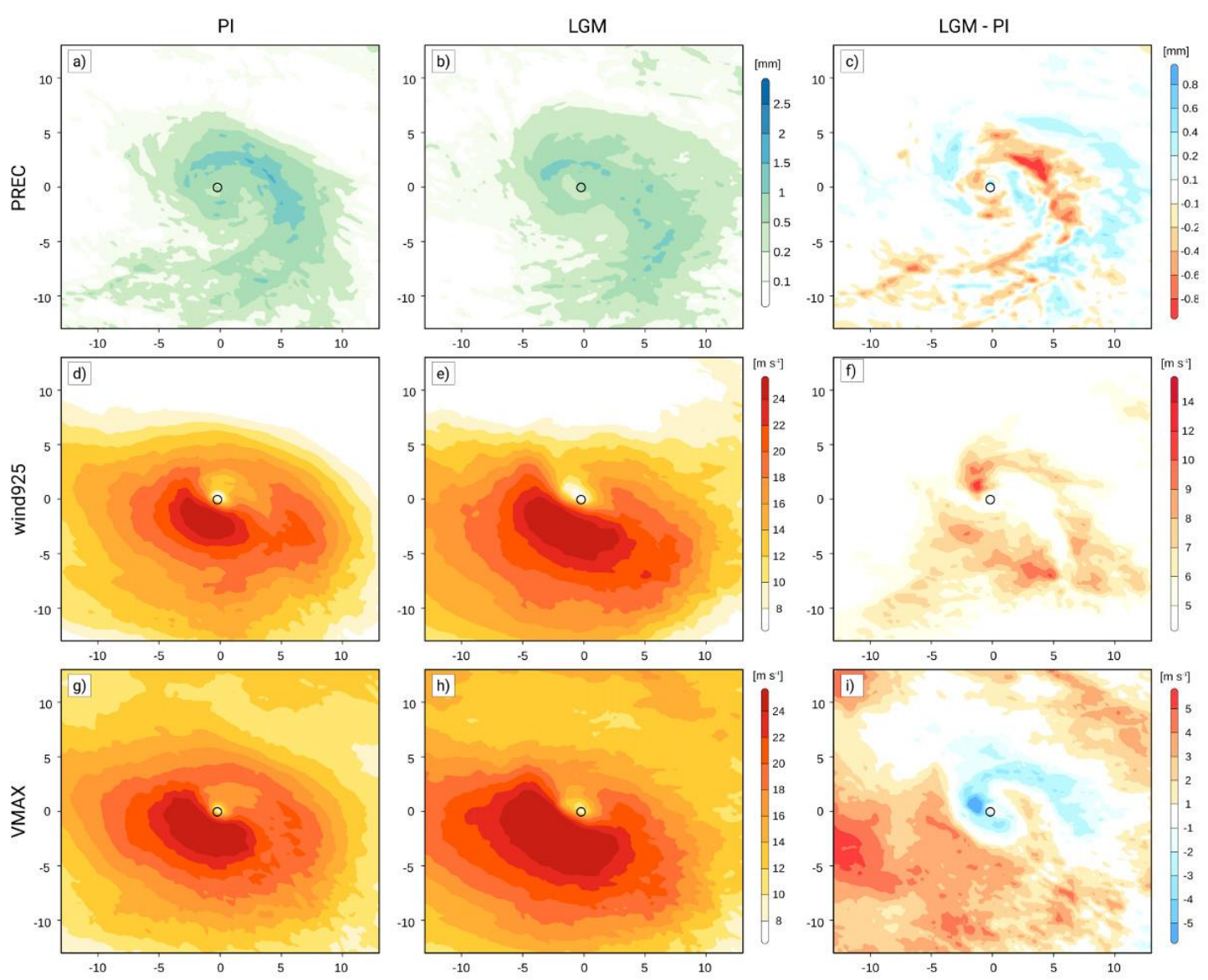

Figure S6. As Figure S4 but for 12 hours after peak intensity. 
Table S1: Summary of wind speed at $925 \mathrm{hPa}$, maximum near surface wind gust and total precipitation of the

35 TOP 30 PI and LGM ensemble with $12.5 \mathrm{~km}$ resolution for 12 hours before / after and at peak intensity. Field mean and maximum corresponds to area depicted in Fig. S4, Fig. S6 and Fig. 8.

\begin{tabular}{|c|c|c|c|c|c|c|c|c|c|c|c|c|}
\hline & \multicolumn{2}{|c|}{$\begin{array}{c}\text { wind } 925 \\
\text { (mean) }[\mathrm{m} / \mathrm{s}]\end{array}$} & \multicolumn{2}{|c|}{$\begin{array}{c}\text { wind } 925 \\
(\max )[\mathrm{m} / \mathrm{s}]\end{array}$} & \multicolumn{2}{|c|}{$\begin{array}{c}\text { VMAX } \\
\text { (mean) }[\mathrm{m} / \mathrm{s}]\end{array}$} & \multicolumn{2}{|c|}{$\begin{array}{c}\text { VMAX } \\
(\max )[\mathrm{m} / \mathrm{s}]\end{array}$} & \multicolumn{2}{|c|}{$\begin{array}{c}\text { PREC (mean) } \\
{[\mathrm{mm} / \mathrm{h}]}\end{array}$} & \multicolumn{2}{|c|}{$\begin{array}{c}\operatorname{PREC}(\max ) \\
{[\mathrm{mm} / \mathrm{h}]}\end{array}$} \\
\hline & PI & LGM & PI & LGM & PI & LGM & PI & LGM & PI & LGM & PI & LGM \\
\hline $\begin{array}{l}-12 \\
\end{array}$ & 9.56 & 1011.37 & 24.71 & 27.23 & $\begin{array}{l}12.46 \\
\end{array}$ & 1414.10 & 23.04 & 25.24 & 0.29 & 0.20 & 3.45 & 2.05 \\
\hline 0 & 10.67 & 12.25 & 25.96 & 27.95 & 13.47 & 15.49 & 26.84 & 26.98 & 0.28 & 0.24 & 3.56 & 2.70 \\
\hline 12 & 11.69 & 12.91 & 26.68 & 28.82 & 14.50 & 16.09 & 28.66 & 30.31 & 0.24 & 0.24 & 1.66 & 1.27 \\
\hline
\end{tabular}

